\title{
Development of Brewed Beverage Search System and Program
}

\author{
Yoichiro Kanno, ${ }^{1,2^{*}}$ Takeshi Onodera, ${ }^{2}$ Toyoaki Kamiya, ${ }^{3}$ and Kiyoshi Toko ${ }^{4,5}$ \\ ${ }^{1}$ Ozeki Co., Ltd., 4-9 Imazu Dezaike, Nishinomiya, Hyogo 663-8227, Japan \\ ${ }^{2}$ Kyushu University, Graduate School of Information Science and Engineering, Kyushu University, \\ 744 Motooka, Nishi-ku, Fukuoka 819-0395, Japan \\ ${ }^{3}$ Cultivate Japan Co., Ltd., 108-1 Kaminokire Izumimachi, Anjo, Aichi 444-1221, Japan \\ ${ }^{4}$ Kyushu University, Institute of Advanced Study, 744 Motooka, Nishi-ku, Fukuoka 819-0395, Japan \\ ${ }^{5}$ Kyushu University, Research and Development Center for Five-Sense Devices, \\ 744 Motooka, Nishi-ku, Fukuoka 819-0395, Japan
}

(Received April 2, 2019; accepted May 29, 2019)

Keywords: taste sensor, sake, wine, sensory evaluation, program

Representation of the "taste" of sake in an easy-to-understand manner is an important issue in the alcohol beverage industry. To visualize the taste of sake and wine in an objective manner, we have developed an application program named "SAKELAVO" to search for brewed beverages on the basis of the results of instrumental analysis using taste sensors as well as sensory evaluation. In this study, with the purpose of developing additional functions of SAKELAVO to meet consumer needs and thus promote the widespread practical use of SAKELAVO, we developed (1) a function to search for products by consumer preference and (2) a function to search for products of similar taste for sake and wine, as well as (3) a function to search for the compatibility of brewed beverages, namely, sake and wine with different foods. As a result, SAKELAVO is now an application that not only visualizes the taste of brewed beverages but also has search functions based on consumer preferences, allowing it to better reflect consumer needs.

\section{Introduction}

Representation of the taste of sake in an easy-to-understand manner is an important issue in the alcohol beverage industry. ${ }^{(1-3)}$ As an approach to this issue, Ozeki Corporation has developed a Sake Flavor Chart by combining instrumental analysis using taste sensors and sensory evaluation by the human sense of taste in a statistical manner. ${ }^{(4-9)}$ Also, Cultivate Japan Co., Ltd. has developed a wine taste search system named iSommelier. ${ }^{(10)}$ In addition, in our previous study, we attempted to visualize the taste of widely consumed brewed beverages, namely, sake and wine, on the basis of the technologies used in the Sake Flavor Chart and iSommelier and developed an application program to search for brewed beverages, which was named SAKELAVO. ${ }^{(11)}$ SAKELAVO has a function of showing the tastes of different sake and wine products in a two-dimensional scatter diagram and a radar chart.

SAKELAVO enables the representation of the taste of brewed beverages in an objective manner. However, assuming the use of this application by general consumers, several additional

*Corresponding author: e-mail: yoichiro.kanno@ozeki.co.jp

https://doi.org/10.18494/SAM.2019.2391 
functions would be needed to meet their needs. ${ }^{(12)}$ In this study, with the purpose of promoting the widespread practical use of SAKELAVO, we developed new functions that are easy to use for consumers. With these extended functions of SAKELAVO, we propose a new common scale for evaluating the taste of brewed beverages in the alcohol beverage industry.

\section{Materials and Methods}

\subsection{SAKELAVO}

In the development of SAKELAVO, we have created a database of sake and wine. The database contains values obtained by taste sensors (TS-5000Z, Intelligent Sensor Technology, Inc.) and sake meter values (specific gravity) for sake, values obtained by taste sensors, and residual sugar values for wine [Table 1(a)]..$^{(13,14)}$ Also, barcodes and images of all products are registered in the database. Sake meter and residual sugar values were determined in accordance with the method prescribed by the National Tax Agency. ${ }^{(15)}$ Also, in our previous research, the tastes of sake and wine were expressed in two-dimensional maps using the SAKELAVO database [Table 1(b), Fig. 1].

Table 1

SAKELAVO database

(a)

\begin{tabular}{lc}
\hline Brewage & Measurement \\
Sake & $\begin{array}{r}\text { Taste sensor [umami, saltiness, sourness, astringency, bitterness, } \\
\text { CPA (bitterness, astringency, umami)], sake meter value }\end{array}$ \\
\hline Wine & $\begin{array}{r}\text { Taste sensor [umami, saltiness, sourness, astringency, bitterness, } \\
\text { CPA (bitterness, astringency, umami)], residual sugar value }\end{array}$ \\
\hline
\end{tabular}

(b)

\begin{tabular}{lcc}
\hline Brewage & Values on abscissa & Values on ordinate \\
\hline Sake & Taste sensor (saltiness) - Sake meter value/10 -1.5 & Sake meter value -3 \\
\hline Wine & Taste sensor (umami) + Taste sensor (biterness) & Reducing sugar \\
\hline
\end{tabular}

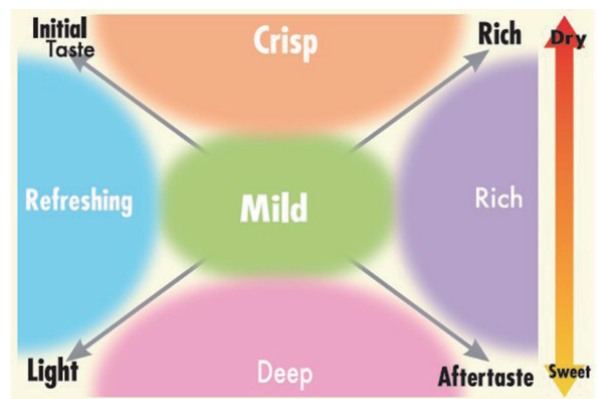

(a)

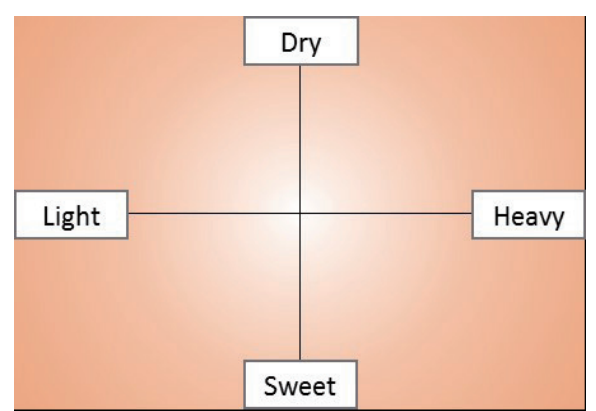

(b)

Fig. 1. (Color online) Two-dimensional maps of (a) sake and (b)wine. 


\subsection{Selection of functions to be developed}

A survey of sake revealed the consumer's image of sake. ${ }^{(16)}$ Also, our previous survey has revealed that consumers have certain needs, as shown in Table 2, when they buy brewed beverages. In this survey, 150 consumers were given a free-form questionnaire. Among these needs, the visualization of taste and the function to search for products using a barcode have already been introduced into SAKELAVO (Fig. 2).

Considering the above consumer needs, in this study, we attempted to develop new functions of SAKELAVO, namely, a function to search for products by preference and a function to search for products of similar taste. We also developed a function to search for the compatibility of brewed beverages with different foods because alcoholic beverages are often served with meals.

Table 2

Consumer needs.

(a)

\begin{tabular}{cc}
\hline a & Consumer demand for alcohol \\
$\mathrm{b}$ & Difficult to understand the taste \\
$\mathrm{c}$ & Don't know what to choose \\
$\mathrm{d}$ & Don't know their favorite taste \\
\hline b) & Want to know the products close to those tasted in the past \\
\hline & Function for the needs of the consumers \\
\hline $\mathrm{a}$ & Visualization of taste \\
$\mathrm{b}$ & Function to search for products using barcodes \\
$\mathrm{c}$ & Function to search for products from taste \\
$\mathrm{d}$ & Function to search for products close to the consumer's favorite taste \\
\hline
\end{tabular}

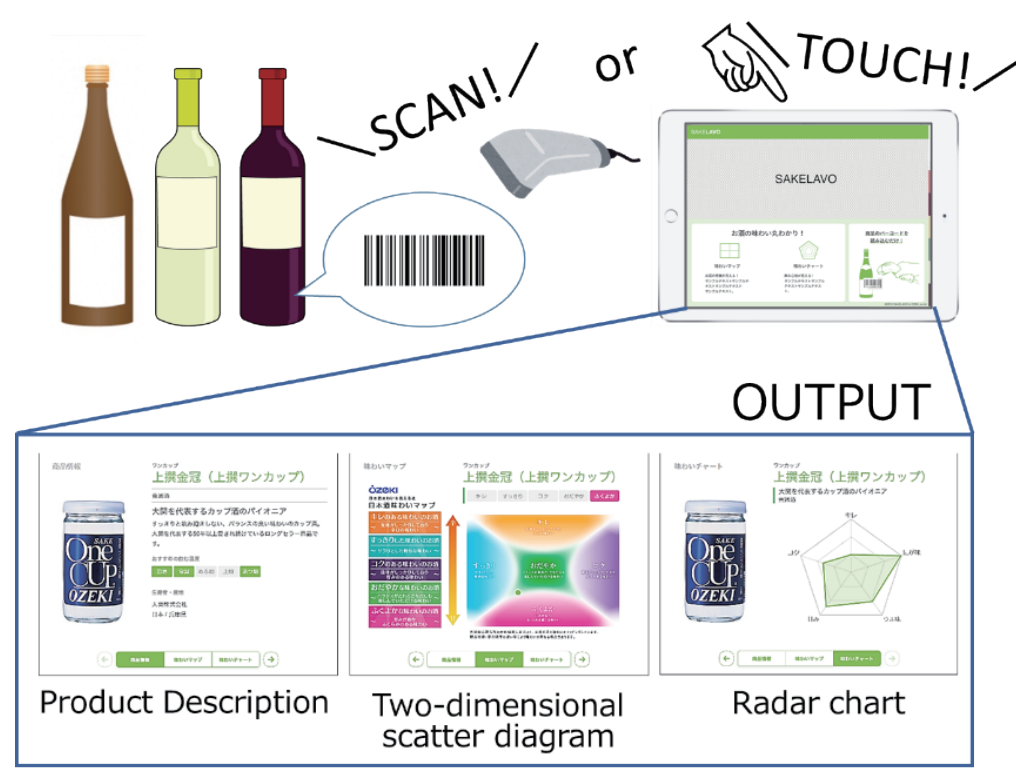

Fig. 2. (Color online) How to use "SAKELAVO". 


\subsection{Development of function to search for products by preference}

One of the consumer comments with regard to buying a brewed beverage is, "I don't know which product matches my taste". To meet their needs, we attempted to develop a function to search for products having a taste close to that desired by the consumers.

SAKELAVO has a function of showing the taste of sake and wine in a two-dimensional scatter diagram. With the conventional function, a consumer can only view the position of a product in the two-dimensional scatter diagram by scanning the barcode of the product using a barcode reader. However, with the new function, a consumer can directly touch the two-dimensional scatter diagram to view a list of products having a taste approximately corresponding to the position he/she touched.

\subsection{Development of function to search for products of similar taste}

Another frequent comment from consumers is, "I'd like to find products with a taste similar to that I enjoyed before". To meet their needs, we attempted to develop a function to search for products that are similar to that previously chosen by consumers.

At present, values such as those obtained by taste sensors as well as sake meters and residual sugar values for 680 types of sake and 3462 types of wine are stored in the database in SAKELAVO. With the newly developed function, the similarity between the product chosen by a consumer and those registered in the database is obtained on the basis of these values. Then the products registered in the database are listed in descending order of similarity.

\subsection{Development of function to search for compatibility of brewed beverages with foods}

The taste of certain foods is particularly compatible with brewed beverages. However, consumers often say, "I don't know what kinds of foods go well with alcoholic beverages".

To meet their needs, we attempted to develop a function suggesting perfect pairings of brewed beverages, namely, sake and wine, and foods to help consumers. With the new function, a consumer can view the list of brewed beverages that go well with certain foods by choosing 5 ingredients and 24 recipes.

\section{Results and Discussion}

\subsection{Function to search for products by preference}

In SAKELAVO, a consumer can view each two-dimensional scatter diagram for sake and wine and choose an arbitrary position on the diagram defined by its $X$ and $Y$ coordinates. Then, the Euclidean distance between the chosen position and the $X$ and $Y$ coordinates of the products registered in the database is obtained using the following equation. 
$[(X$ coordinate of position chosen by consumer

$-X$ coordinate of product registered in database $)^{2}$

$+(Y$ coordinate of position chosen by consumer

$-Y$ coordinate of product registered in database $\left.)^{2}\right]^{1 / 2}$

The smaller the obtained value, the closer the taste of a product to that chosen by the consumer. These products are listed and displayed in ascending order of the obtained values (Fig. 3).

\subsection{Function to search for products of similar taste}

In SAKELAVO, a consumer can choose a product from the product list of sake and wine. The equation used to calculate the similarity between the product chosen by the consumer and those registered in the database was created using the values stored in the database (values obtained by taste sensors, sake meter values, and residual sugar values).

In this calculation, the taste of a product is considered as a collection of values chosen from the database of brewed beverages, and each value is considered as an independent variable. On the basis of the idea that the smaller the dispersion of these variables, the more similar the taste of two products, we calculated the $F$ value as an index of the homoscedasticity of the variance.

In this equation, the value of each variable multiplied by a suitable weighted value is used instead of that of an analysis item. The weighted value used is divided by the sum of the weighted values of all analysis items used in the equation (Table 3). These values are determined by the actual sensory evaluations by sake and wine specialized sensory evaluators that we defined.

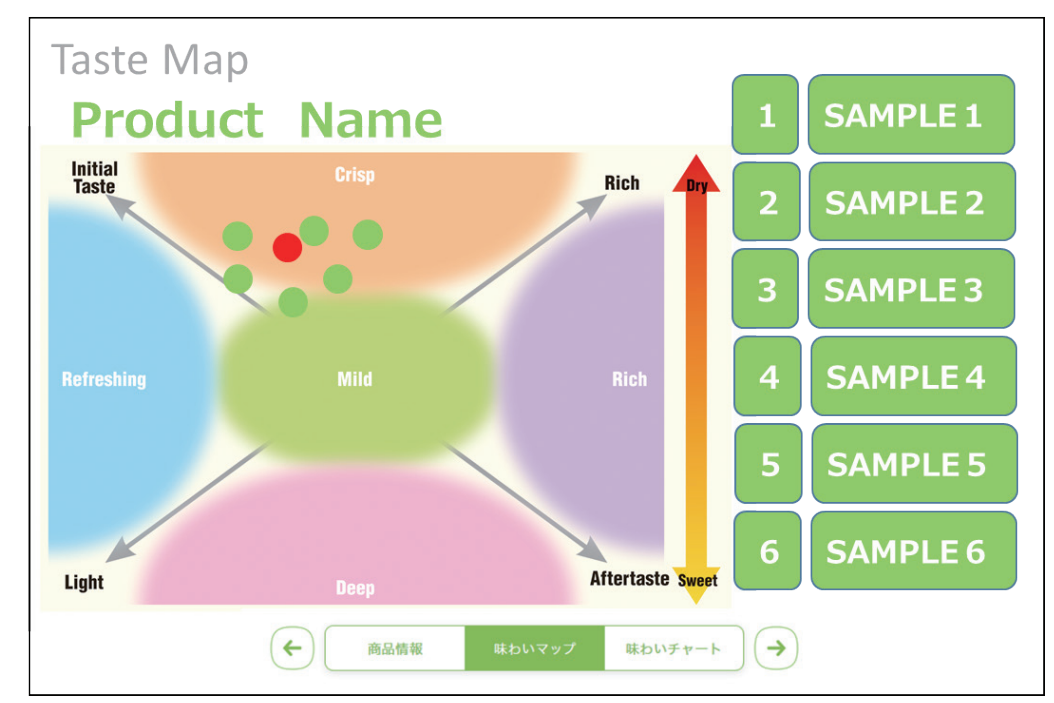

Fig. 3. (Color online) Output screen of a function to search for products by consumer preference. Red circle: consumer-selected product. Green circle: products close to the position selected by the consumer. 
Table 3

Weighted value of analysis item.

\begin{tabular}{|c|c|c|c|c|c|c|c|c|}
\hline \multirow[t]{2}{*}{ Sake } & Umami & Saltiness & Sourness & Astringency & Bitterness & $\begin{array}{c}\text { CPA } \\
\text { (bitterness) }\end{array}$ & $\begin{array}{c}\mathrm{CPA} \\
\text { (astringency) }\end{array}$ & $\begin{array}{c}\text { CPA } \\
\text { (umami) }\end{array}$ \\
\hline & 2 & 1 & 1 & 1 & 2 & 1 & 1 & 1 \\
\hline \multirow[t]{2}{*}{ Wine } & Umami & Saltiness & Sourness & Astringency & Bitterness & $\begin{array}{c}\text { CPA } \\
\text { (bitterness) }\end{array}$ & $\begin{array}{c}\mathrm{CPA} \\
\text { (astringency) }\end{array}$ & $\begin{array}{c}\text { CPA } \\
\text { (umami) }\end{array}$ \\
\hline & 1 & 1 & 1 & 0 & 2 & 2 & 1 & 1 \\
\hline \multirow[t]{2}{*}{ Sake } & \multicolumn{2}{|c|}{ Sake meter value } & \multicolumn{2}{|c|}{$\begin{array}{c}(-2 \times \text { Sourness }- \text { Sake } \\
\text { meter value }) / 3\end{array}$} & \multicolumn{2}{|c|}{$\begin{array}{c}\text { Saltiness }- \text { Sake } \\
\text { meter value } / 10-1.5\end{array}$} & Sake meter value & Total \\
\hline & \multicolumn{2}{|c|}{1} & \multicolumn{2}{|c|}{3} & \multicolumn{2}{|c|}{2} & 2 & 18 \\
\hline \multirow{2}{*}{ Wine } & \multicolumn{2}{|c|}{ Fruit taste } & \multicolumn{2}{|c|}{ Reducing sugar } & & & & Total \\
\hline & 2 & & & 3 & & & & 14 \\
\hline
\end{tabular}

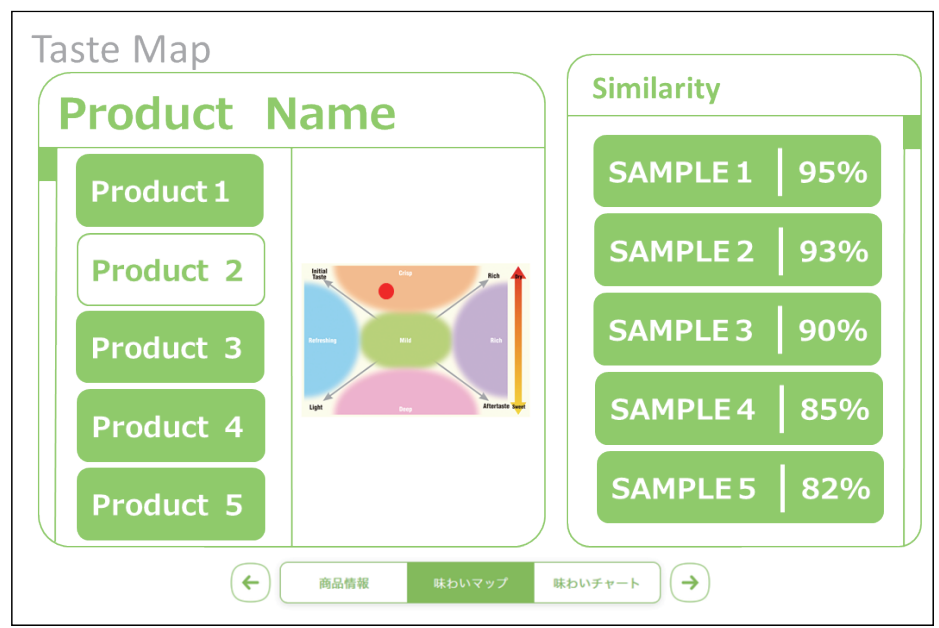

Fig. 4. (Color online) Output screen of a function to search for products of similar taste for sake and wine.

It is considered that the smaller the calculated $F$ value, the closer the dispersion of variables between two products, namely, the more similar the taste of the products. The products are listed in ascending order of the $F$ value (Fig. 4). Then, the $P$ value of the analysis of variance using the $F$ value was taken as the disagreement between two products, and it was regarded as the "similarity" by subtracting it from 1 .

\subsection{Function to search for compatibility of brewed beverages with foods}

We developed a system to define the compatibility between brewed beverages (sake and wine) and foods as described below. First, taste categories were set for brewed beverages (sake and wine) and foods. Brewed beverages were classified according to their qualities and taste (Table 4).

More specifically, each type of sake was classified according to its specific class and its area in the two-dimensional scatter diagram, while each type of wine was classified according to its color and its area in the two-dimensional scatter diagram. Foods were classified according to their main ingredient and recipe (Table 5). 
Then, a category of foods was combined with a category of brewed beverages that are considered to go well with that category of foods (Table 6). These categories are determined by actual sensory evaluations and discussions by sake and wine specialized sensory evaluators.

Table 4

Taste categories for brewed beverages.

\begin{tabular}{lccc}
\hline \multirow{2}{*}{ Sake } & Specific class & \multicolumn{2}{c}{ "Futsuu", "Honjozo", "Junmai", "Ginjo", "Daiginho", "Junmai-Ginjo", "Junmai-Daiginjo" } \\
\cline { 2 - 4 } & \multirow{2}{*}{ SAKE Flavor Chart } & $X$ & left(1), middle(2), right(3) \\
\cline { 2 - 3 } Wine & Color & up(1), middle(2), down(3) \\
\cline { 2 - 4 } & Taste map & $X$ & Green, White, Yellow, Red, Brown, Rose \\
\cline { 2 - 3 } & & $Y$ & left(1), middle(2), right(3) \\
\hline
\end{tabular}

Table 5

Taste categories for foods.

\begin{tabular}{lc}
\hline Vegetables & Raw, Bake, Boil, Fry, Simmer \\
Fish & Raw, Bake, Boil, Fry, Simmer \\
Meet & Raw, Bake, Boil, Fry, Simmer \\
Pasta & Oil, Tomato, Cream \\
Cheese & Fresh, Bloomy rind, Blue, Goat milk, Washed rind, Hard, Semihard \\
\hline
\end{tabular}

Table 6

Taste categories for foods.

\begin{tabular}{|c|c|c|c|c|c|c|c|}
\hline & \multicolumn{3}{|c|}{ Sake } & \multicolumn{3}{|c|}{ Wine } \\
\hline & & \multirow{2}{*}{ Specific class ${ }^{(a)}$} & \multicolumn{2}{|c|}{ SAKE Flavor Chart } & \multirow{2}{*}{ Color $^{(b)}$} & \multicolumn{2}{|c|}{ Taste map } \\
\hline & & & $X$ & $Y$ & & $X$ & $Y$ \\
\hline \multirow{5}{*}{ Vegetables } & Raw & $\mathrm{F}, \mathrm{H}, \mathrm{J}$ & 1,2 & 2 & $\mathrm{G}, \mathrm{W}, \mathrm{Ro}$ & 1 & 1 \\
\hline & Bake & $\mathrm{F}, \mathrm{H}, \mathrm{J}$ & 2 & 1,2 & $\mathrm{G}, \mathrm{W}, \mathrm{Ro}$ & 2 & 1 \\
\hline & Boil & $\mathrm{JD}, \mathrm{JG}, \mathrm{J}$ & 2 & 2,3 & W, Y, R, Ro & 2 & 2 \\
\hline & Fry & JD, JG, D, G & 1,2 & 2,3 & G, W, Y, Ro & 1 & 2 \\
\hline & Simmer & $\mathrm{D}, \mathrm{G}, \mathrm{H}, \mathrm{F}$ & 1,2 & 1 & G, W, Y, Ro & 1 & 1,2 \\
\hline \multirow{5}{*}{ Fish } & Raw & $\mathrm{F}, \mathrm{H}, \mathrm{J}$ & 1,2 & 1,2 & G, W, Ro & 1 & 1,3 \\
\hline & Bake & F, H, J & 2 & 1,2 & G, W, R, Ro & 2 & 1,3 \\
\hline & Boil & $\mathrm{JD}, \mathrm{JG}, \mathrm{J}$ & $1,2,3$ & 3 & G, W, Ro & 2,3 & 2 \\
\hline & Fry & $\mathrm{D}, \mathrm{G}, \mathrm{H}, \mathrm{F}$ & $1,2,3$ & 1 & $\mathrm{G}, \mathrm{W}, \mathrm{R}, \mathrm{B}, \mathrm{Ro}$ & 2,3 & 2 \\
\hline & Simmer & JD, JG, J & 2,3 & 2,3 & W, B, Ro & 3 & 2 \\
\hline \multirow{5}{*}{ Meet } & Raw & $\mathrm{D}, \mathrm{G}, \mathrm{H}$ & 1,2 & 1 & W, Y, R, Ro & 1,2 & 1,2 \\
\hline & Bake & F, H, J & 2,3 & 1,2 & Y, R, B, Ro & 3 & 2,3 \\
\hline & Boil & $\mathrm{JD}, \mathrm{JG}, \mathrm{J}$ & 1,2 & 2,3 & W, Y, R, B, Ro & 1,2 & 2,3 \\
\hline & Fry & F, H, J & $1,2,3$ & 1 & $\mathrm{G}, \mathrm{W}, \mathrm{Y}, \mathrm{R}, \mathrm{B}, \mathrm{Ro}$ & 3 & 2,3 \\
\hline & Simmer & JD, JG, J & 3 & 2,3 & Y, R, B, Ro & 3 & 2,3 \\
\hline \multirow{3}{*}{ Pasta } & Oil & JD, JG, D, G & $1,2,3$ & 2 & G, W, Ro & 1,2 & 1,2 \\
\hline & Tomato & $\mathrm{D}, \mathrm{G}, \mathrm{H}$ & $1,2,3$ & 1 & W, R, Ro & 2 & 1,2 \\
\hline & Cream & JD, JG, J & $1,2,3$ & 3 & W, Y, Ro & 2,3 & 2,3 \\
\hline \multirow{6}{*}{ Cheese } & Fresh & $\mathrm{F}, \mathrm{H}, \mathrm{J}$ & 1 & $1,2,3$ & G, W, Ro & 1 & 3 \\
\hline & Bloomy rind & $\mathrm{JD}, \mathrm{JG}, \mathrm{D}, \mathrm{G}$ & $1,2,3$ & 3 & $\mathrm{~W}, \mathrm{~T}, \mathrm{R}, \mathrm{B}$ & 2,3 & 2,3 \\
\hline & Blue & JD, JG, J & 3 & $1,2,3$ & Y, R, B, Ro & 2,3 & 2,3 \\
\hline & Goat milk & $\mathrm{JD}, \mathrm{JG}, \mathrm{J}$ & 2,3 & 1,2 & G, W, Ro & 3 & 3 \\
\hline & Washed rind & $\mathrm{JD}, \mathrm{JG}, \mathrm{J}$ & 2,3 & 2,3 & Y, R, B & 2,3 & 2,3 \\
\hline & Hard, Semihard & F, H, J & 1,2 & 1,2 & $\mathrm{~W}, \mathrm{Y}, \mathrm{R}, \mathrm{B}$ & 2,3 & 2,3 \\
\hline
\end{tabular}

${ }^{(a)}$ F: Futsu-shu, H: Honjozo, J: Junmai, JD: Junmai-Daiginjo, JG: Junmai-Ginjo, D: Daiginjo, and G: Ginjo

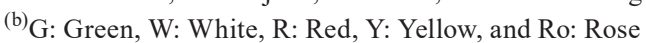




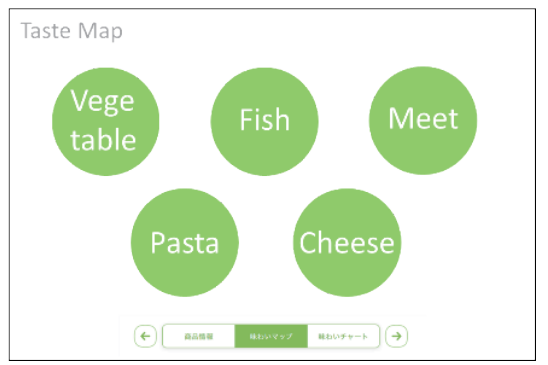

(a)

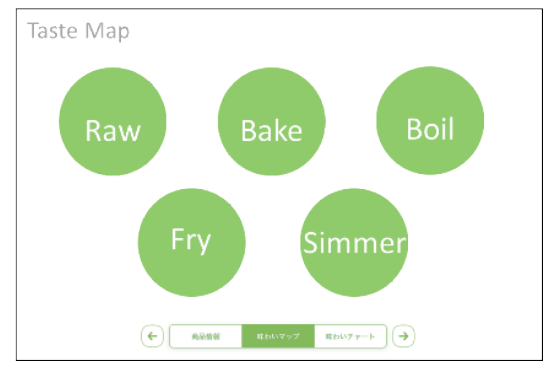

(b)

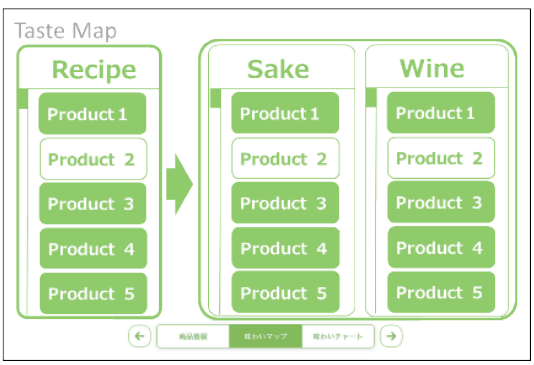

(c)

Fig. 5. (Color online) Output screen of a function to search for the compatibility of brewed beverages with different foods.

As described above, we developed the system to evaluate the compatibility of brewed beverages with foods and introduced it into SAKELAVO. In SAKELAVO, consumers can choose a category, namely, the ingredient and recipe, of their favorite foods. Then, a list of brewed beverages that are considered to go well with the combination of the ingredient and recipe is displayed (Fig. 5). Note that the data used here is on foods and seasonings that are judged to go well with the general classification category of brewed beverages.

\section{Conclusion}

We considered how to develop additional functions of SAKELAVO to meet consumer needs and, as a result, successfully developed search functions to find products by consumer preference or by the taste of brewed beverages as well as a function to search for the compatibility of brewed beverages with foods. The function to search for products by preference enables consumers to find products with a taste that approximately corresponds to the position they touched on a two-dimensional scatter diagram. In the development of the function to search for products of similar taste, we created an equation to obtain the similarity of brewed beverages registered in the SAKELAVO database based on their taste. In the development of the function to search for the compatibility of brewed beverages with foods, we created a flowchart to derive compatibility between brewed beverages and foods by classifying brewed beverages and foods according to their taste and defining the compatibility between them.

Using SAKELAVO with these extended functions, consumers can view the taste of brewed beverages in a two-dimensional scatter diagram and a radar chart by a simple operation. Also, they can search for brewed beverages with their desired taste as well as find brewed beverages compatible with foods.

If SAKELAVO becomes widely used and accepted as a common tool for representing the taste of brewed beverages, it can be further developed into a communication tool that enables consumers not only to understand their own preferences but also to exchange common information about the taste of brewed beverages. 
We will further extend this study to eliminate the barrier between heavy and light users of brewed beverages and help them find a freer and more intuitive way to enjoy alcoholic beverages.

\section{Acknowledgments}

This work was partly supported by JST-Mirai Program Grant Number JPMJMI 18D8, Japan.

\section{References}

1 S. Sato, H. Kawashima, and Y. Maruyama: J. Brew. Soc. Jpn. 69 (1974) 774 (in Japanese).

2 Sake Service Institute: Basics of Sake - for Professionals of Sake-, Textbook (Sake Service Institute, Tokyo, 2009) p. 110 (in Japanese).

3 H. Utsunomiya: J. Jpn. Assoc. Odor Environ. 38 (2007) 352 (in Japanese).

4 K. Otubo, H. Ikezaki, A. Taniguchi, H. Okadome, H. Toyoshima, and T. Inbe: IEEE Tech. Rep., OME 2000-62 (2000).

5 Y. Tahara and K. Toko: IEEE Sens. J. 13 (2013) 3001.

6 K. Toko, D. Hara, Y. Tahara, M. Yasuura, and H. Ikezaki: Sensors 14 (2014) 16274.

7 R. Liu, X. Gao, J. Wang, L. Dai, B. Kang, L. Zhang, J. Shi, X. Gui, P. Liu, and X. Li: Sens. Mater. 29 (2017) 105.

8 J. Liu, J. Yang, W. Wang, S. Fu, Y. Shi, and H. Meu: Sens. Mater. 28 (2016) 785.

9 Y. Kanno, T. Minetoki, T. Bogaki, T. Onodera, and K. Toko: Sens. Mater. 30 (2018) 1197.

10 Cultivate Japan Co., Ltd.: iSommelier, http://isommelier.net/ (accessed November 2017) (in Japanese).

11 Y. Kanno, T. Kamiya, T. Onodera, and K. Toko: Jpn. J. Taste Smell Res. 25 (2018) S25 (in Japanese).

12 National Tax Agency: Study on the Sound Development of Sake-Brewing Industry: http://www.nta.go.jp/ taxes/sake/kasseika/hokoku/01.htm (accessed March 2019) (in Japanese).

13 S. Nakayama, H. Saito, H. Sakurai, H. Nakai, and H. Ikezaki: Iwate Ind. Res. Inst. Res. Rep. 2 (1995) 97 (in Japanese).

14 K. Toko, Y. Tahara, M. Habara, Y. Kobayashi, and H. Ikezaki: Essentials of Machine Olfaction and Taste, Ed. T. Nakamoto (Wiley, New York, 2016) Chap. 4, p. 87.

15 N. Nishitani: Prescription Method of National Tax Agency (Brewing Society of Japan, Tokyo, 1974) (in Japanese).

16 Japan Sake and Shochu Makers Association: Drinking trend survey of Japanese, https://www.sakagura-press. com/sake/japan-inshu2017/ (accessed April 2019) (in Japanese). 